\title{
REVIEW \\ Erectile dysfunction and heart failure: the role of phosphodiesterase type 5 inhibitors
}

\author{
H Al-Ameri ${ }^{1}$ and RA Kloner ${ }^{1,2}$ \\ ${ }^{1}$ The Heart Institute, Good Samaritan Hospital, Los Angeles, CA, USA and ${ }^{2}$ Department of Internal Medicine, Division of \\ Cardiovascular Medicine, Keck School of Medicine, University of Southern California, Los Angeles, CA, USA
}

\begin{abstract}
The phosphodiesterase type 5 (PDE-5) inhibitors are effective in treating erectile dysfunction (ED). ED and heart failure (HF) share similar risk factors, and commonly present together. This association has led to questions ranging from the safety and efficacy of PDE-5 inhibitors in HF patients to a possible role for this class of medication to treat HF patients with or without ED. In addition to endothelial dysfunction, there are causes of ED specific to patients with HF including low exercise tolerance, depression and HF medications. Before treating HF patients with PDE-5 inhibitors, patients should be assessed for their risk of a cardiac event during sexual activity. PDE-5 inhibitors are safe and effective in treating ED in HF patients. An improvement in erectile function by PDE-5 inhibitors was associated with an improvement in quality of life and reduction in depression. Several studies demonstrated the effect of PDE-5 inhibitors on HF per se. PDE-5 inhibitors improved endothelial dysfunction, increased exercise tolerance, decreased pulmonary vascular resistance and pulmonary artery pressure, and increased cardiac index. Several mechanisms whereby PDE-5 inhibitors improve HF have been proposed. PDE-5 inhibitors already have a role in treating primary pulmonary hypertension; however additional studies are needed to determine if they will become a standard therapy for HF patients.

International Journal of Impotence Research (2009) 21, 149-157; doi:10.1038/ijir.2009.11; published online 23 April 2009
\end{abstract}

Keywords: heart failure; phosphodiesterase 5 inhibitor; mechanism; safety; efficacy

\section{Introduction}

Since the release of sildenafil, a phosphodiesterase type 5 (PDE-5) inhibitor, in March 1998, this class of medicines has become the first line of therapy for millions of men with erectile dysfunction (ED). ${ }^{1}$ In 2003, vardenafil and tadalafil were added to the list of approved PDE-5 inhibitors. The mechanism of action of PDE-5 inhibitors is well understood, and their efficacy in treating ED is well established. ${ }^{2}$ However, the role of PDE-5 inhibitors as potential therapy for other diseases is still under investigation. The three PDE-5 inhibitors each reduce endothelial dysfunction. ${ }^{3-6}$ As a result of the

Correspondence: Dr RA Kloner, The Heart Institute, Good Samaritan Hospital, 1225 Wilshire Boulevard, Los Angeles, CA 90017, USA.

E-mail: rkloner@goodsam.org

Received 20 February 2009; revised 27 March 2009; accepted 27 March 2009; published online 23 April 2009 endothelial dysfunction that can occur with some types of ED, links between cardiovascular diseases and ED have been discovered. ${ }^{7,8} \mathrm{ED}$ is associated with coronary artery disease, ${ }^{9}$ hypertension ${ }^{10}$ and now heart failure (HF). ${ }^{11}$

The goal of this review is to describe the prevalence of ED in HF patients, causes of ED specific to patients with HF, the cardiac risk assessment of sexual activity, the safety of PDE-5 inhibitors to treat ED in HF patients, the efficacy of PDE-5 inhibitors for ED in HF patients, the hemodynamic effects of PDE-5 inhibitors on HF, the potential mechanisms by which PDE-5 inhibitors improve $\mathrm{HF}$ and role of PDE-5 inhibitors in pulmonary hypertension.

\section{Prevalence of ED in patients with HF}

The prevalence of HF in the United States is estimated at 5.3 million by the American Heart Association. ${ }^{12}$ The Massachusetts Male Aging study 
reported that of healthy men between the ages of 40 and 70 years, approximately $52 \%$ had some degree of ED. ${ }^{13}$ Because cardiovascular disease and ED share similar risk factors, it is not surprising to find that many patients have both conditions. It is estimated that $60-89 \%$ of $\mathrm{HF}$ patients have some degree of ED. ${ }^{14-16}$ One study of $329 \mathrm{HF}$ patients demonstrated a prevalence of ED that was 81, 90 and $91 \%$ in Hispanic, black and white men. There was no statistically significant difference in severity among the three groups. ${ }^{15}$ These studies strengthened the link between ED and HF.

\section{Causes of ED in patients with HF}

Table 1 summarizes the causes of ED that are specific to HF patients. Inadequate exercise capacity can increase performance anxiety, which further worsens ED, and may lead to depression. HF, ED and depression have been described as a triad of conditions that reciprocally exacerbate each other. ${ }^{17}$ Atherosclerosis is a common cause of $\mathrm{HF}$, and its pathogenesis begins with endothelial dysfunction, with eventual development of atherosclerotic plaques that obstruct blood flow. The obstruction may also occur in the arteries that supply the corpus cavernosum. Thiazide diuretics, digoxin, aldosterone and traditional $\beta$-blockers have been linked to ED. ${ }^{18-21}$ However some third generation $\beta$-blockers and angiotensin receptor blockers have been associated with improvement of ED due to their protective effects on penile tissue and endothelial function. $^{22-25}$ In summary, causes of ED in HF patients are decreased exercise capacity, depres- sion, endothelial dysfunction and standard $\mathrm{HF}$ medications.

\section{Cardiac risk assessment and safety of sexual activity in HF patients}

The Second Princeton Consensus provides guidelines for assessing risk for sexual activity in patients with a cardiac history. Patients are stratified into one of three groups. Low risk includes asymptomatic patients with less than three cardiac risk factors, mild stable angina, more than 6 weeks postmyocardial infarction, New York Heart Association (NYHA) class I HF or mild valvular disease. Intermediate risk includes asymptomatic patients with more than three cardiac risk factors, moderate stable angina, between 2 and 6 weeks post-myocardial infarction or NYHA class II HF. High risk includes unstable angina, uncontrolled hypertension, NYHA class III or IV HF, less than 2 weeks post-myocardial infarction or moderate-to-severe valvular dysfunction. If patients are low risk, then resuming sexual activity is recommended. If patients are high risk, then it is recommended that sexual activity be postponed until the patient is stabilized. If patients are intermediate risk, assessment with cardiac testing is recommended to allow restratification into either low or high risk. ${ }^{26}$

Studies reporting the clinical and physiological effects of sexual activity in patients with HF are sparse. The amount of energy that is involved in sexual activity from the preorgasmic to orgasmic phase is approximately $2.0-4.0$ metabolic equivalents of the tasks. This is roughly equivalent to doing easy housework or climbing a flight of stairs. ${ }^{27}$ It is reasonable to think that HF patients who have this

Table 1 Causes of ED in HF patients

\begin{tabular}{|c|c|}
\hline Causes & Mechanisms \\
\hline Decreased exercise capacity & $\begin{array}{l}\text { Impaired increase in stroke volume leads to inadequate cardiac output for exercise or sexual } \\
\text { activity }\end{array}$ \\
\hline Psychiatric & $\begin{array}{l}\text { Performance anxiety secondary to poor exercise tolerance } \\
\text { Depression } \\
\text { Psychiatric medications }\end{array}$ \\
\hline \multicolumn{2}{|l|}{ Atherosclerosis } \\
\hline Endothelial dysfunction & $\begin{array}{l}\text { Loss of vasodilation } \\
\text { Increased vasoconstrictors }\end{array}$ \\
\hline Atherosclerotic plaques & Decreased blood flow to corpus cavernosum \\
\hline \multicolumn{2}{|l|}{ Medications } \\
\hline Thiazide diuretics & Mechanism unclear \\
\hline Digoxin & Inhibition of sodium pump activity alters smooth muscle activity in corpus cavernosum tissue \\
\hline Aldosterone & Enhance contractile response of penile corpus cavernosum tissue to norepinephrine \\
\hline Traditional $\beta$-blockers & Mechanism unclear \\
\hline
\end{tabular}


amount of exercise capacity can safely tolerate sexual activity. In a letter to the editor, Cremers et $a l^{28}$ reported the case of a 53-year-old man with $\mathrm{HF}$ and secondary pulmonary hypertension with an ambulatory hemodynamic monitor. The author demonstrated that sexual activity affected the heart differently compared to similar physical exercise. The patient did not complain of any adverse events during intercourse, yet had larger increases of right ventricular systolic pressure, right ventricular diastolic pressure and estimated pulmonary artery pressure during sexual activity compared to physical activity of similar metabolic equivalents achieved by brisk walking. This discrepancy may have been due to the psychological anticipation and sympathetic activation associated with sexual activity or the position of the patient during sexual activity and physical exercise. Right ventricular pressures in a supine HF patient may be elevated compared to a standing patient. This case report demonstrated that additional studies are needed to elucidate the physiological effects that sexual activity has on HF patients.

\section{Efficacy of PDE-5 inhibitors for ED in patients with $\mathrm{HF}$}

Table 2 summarizes studies demonstrating PDE-5 inhibitors' efficacy for treating ED in patients with HF. Katz et $a .^{29}$ performed a study to determine sildenafil's effect in patients with stable chronic HF. This placebo-controlled, double-blinded study treated 137 patients with either flexible dosing sildenafil or placebo for 12 weeks. Patients were given the International Index of Erectile Function questionnaire at the start and end of the 12-week study period. The primary outcomes of the study were the third question pertaining to the patient's ability to achieve penetration and the fourth question pertaining to the patient's ability to maintain an erection until the completion of intercourse. The results showed that there was a statistically significant improvement on questions 3 and 4 . This study demonstrated that sildenafil was effective in treating ED in stable HF patients.

Webster et al. ${ }^{30}$ performed a placebo-controlled, double-blinded, crossover study of 35 patients with NYHA class II and III HF and ED who were treated with sildenafil. In addition to the International Index of Erectile Function questionnaire, patient's quality of life and mood were assessed with the Minnesota Living with Heart Failure Questionnaire and the Beck Depression Index. Patients had a significant improvement in ED, depression and quality of life assessed by the questionnaires. Freitas et $a l^{31}$ also performed a study evaluating the efficacy of sildenafil for ED in HF patients. In their study, 12 patients with ejection fraction $<40 \%$ received sildenafil for 1 month. Patients answered the International Index of Erectile Function questionnaire and the Minnesota Living with Heart Failure Questionnaire before and 1 month after treatment with sildenafil. Sildenafil caused a significant improvement in both erectile function and quality of life. In summary, studies performed to date show that the PDE-5 inhibitor sildenafil is effective in treating ED in patients with HF; whether the other PDE-5 inhibitors are effective in this patient cohort remains to be determined.

\section{Safety of PDE-5 inhibitors in HF patients}

Common adverse effects of PDE-5 inhibitors are generally related to either the vasodilatory (for example, headache or flushing) or gastrointestinal (for example, dyspepsia or reflux) effects. Less commonly described adverse affects are visual complaints (for example, blue-green color tinge or blurry vision) or myalgias. ${ }^{32}$ Nitrates are contraindicated during PDE-5 inhibitor use due to hypotension. As sildenafil and vardenafil have approximately $4 \mathrm{~h}$ half-lives, nitrates should be

Table 2 Efficacy of treating ED with sildenafil in HF patients

\begin{tabular}{|c|c|c|c|c|c|c|c|}
\hline Study & $\mathrm{n}$ & Type of study & $\begin{array}{l}\text { Length of } T x \\
\quad \text { (weeks) }\end{array}$ & $\begin{array}{l}\text { IIEF questions } \\
\text { evaluated }\end{array}$ & Baseline & Post Tx & p-value \\
\hline Katz et al. ${ }^{29}$ & 137 & Rand, PC, DB & 12 & $\begin{array}{l}\text { Q3 } \\
\text { Q4 }\end{array}$ & $\begin{array}{l}1.7 \\
1.4\end{array}$ & $\begin{array}{l}2.8 / 3.7 \\
2.4 / 3.3 \\
(\mathrm{P} / \mathrm{S})\end{array}$ & $\begin{array}{l}0.0003^{*} \\
0.0012^{*}\end{array}$ \\
\hline Webster et al. ${ }^{30}$ & 35 & Rand, PC, DB, Cross & 6 & Q1-5, 15 & $\sim 9$ & $\sim 16$ & $<0.001^{\dagger}$ \\
\hline Freitas et al. ${ }^{31}$ & 12 & Prospective & 4 & IIEF5 & 9.6 & 19.3 & $0.0001^{\dagger}$ \\
\hline
\end{tabular}

Abbreviations: Cross, crossover; DB, double blind; IIEF, International Index of Erectile Function; IIEF5, abbreviated version of IIEF with 5 questions; $n$, number of patients; P, placebo; PC, placebo control; Q, question; Rand, randomized; S, sildenafil; Tx, treatment.

* Significance between sildenafil and placebo post-treatment values for each question.

${ }^{\dagger}$ Significance between post-treatment and baseline values. 
avoided for at least $24 \mathrm{~h} .{ }^{33}$ Tadalafil has a half-life of $17.5 \mathrm{~h}$ that prolongs the risk of severe hypotension with concomitant use of nitrates. Kloner et al. ${ }^{34}$ demonstrated that nitrates should be avoided for $48 \mathrm{~h}$ after tadalafil use. If a patient should develop hypotension secondary to concomitant use of nitrates and PDE-5 inhibitors, then treatment recommended by the American College of Cardiology consensus statement should include placing the patient in the Trendelenburg position, fluid administration and possible further blood pressure support with $\alpha$ - and $\beta$-adrenergic agonists or an intraaortic balloon pump. ${ }^{26,32}$

Patients with HF are not exempt from the above adverse effects of PDE-5 inhibitors. However, does the impaired left ventricular function put $\mathrm{HF}$ patients at increased risk for adverse effects with PDE-5 inhibitors? Katz et al. ${ }^{29}$ evaluated the safety of flexible dosing of sildenafil in $137 \mathrm{HF}$ patients for 12 weeks. Among them, $60 \%$ of the treatment group and $48 \%$ of the placebo group developed adverse events; only 3 and $5 \%$, respectively, were serious adverse events. Only two patients from each group discontinued treatment secondary to the adverse event. In a study by Webster et al. ${ }^{30}$ there were no reports of any adverse effects among $35 \mathrm{HF}$ patients receiving sildenafil treatment over a 6 -week period. In a study by Freitas et al. ${ }^{31}$ only 1 of $12 \mathrm{HF}$ patients complained of mild headache and visual change associated with sildenafil treatment over a 4-week period. These studies demonstrated that it was safe to treat stable HF patients with sildenafil for their $\mathrm{ED}$, and that their reduced left ventricular function did not put them at increased risk for adverse effects. However, it is important to note that these patients did not have HF secondary to aortic stenosis or hypertrophic obstructive cardiomyopathy. Vasodilating medications, including the PDE-5 inhibitors, are generally avoided in patients with aortic stenosis or hypertrophic obstructive cardiomyopathy because of a possible increase in outflow gradient and hypotension.

\section{Effects of PDE-5 inhibitors on HF}

\section{Acute studies}

Table 3 summarizes the short-term effects of PDE- 5 inhibitors on HF. Bocchi et al..$^{35}$ performed a doubleblind, placebo-controlled, crossover study that evaluated sildenafil's effect on exercise and neurohormonal activation in patients with HF. A total of 23 men with HF were given either placebo or $50 \mathrm{mg}$ of sildenafil approximately $1 \mathrm{~h}$ before a $6 \mathrm{~min}$ treadmill-walking test and a maximal exercise stress test on day 1, and then crossed over to the other medicine before exercise testing on the next day. Hemodynamics were recorded for each group and compared. Sildenafil reduced basal heart rate and

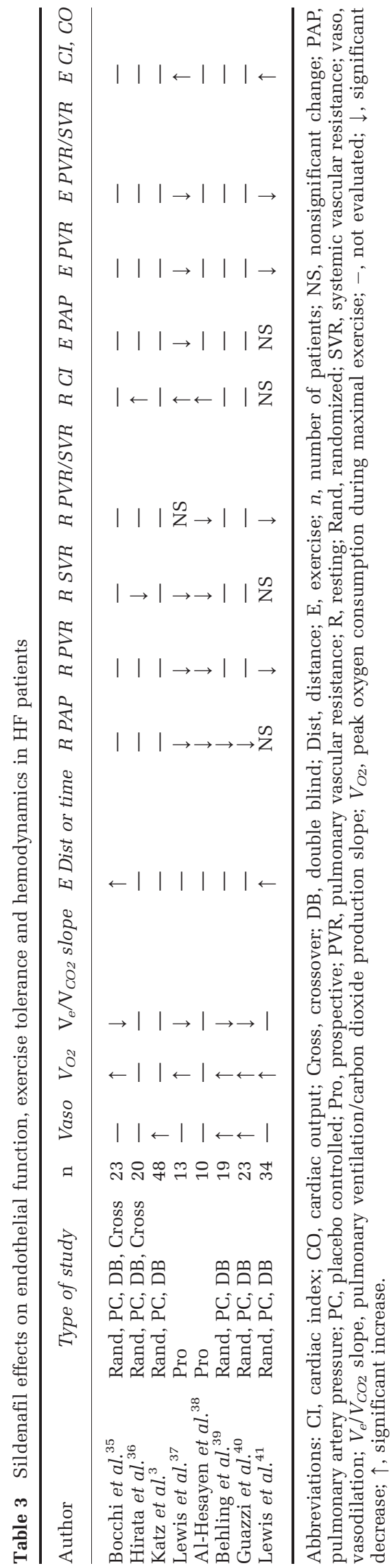


systolic and diastolic blood pressure. The heart rate throughout the $6 \mathrm{~min}$ treadmill-walking test was also significantly decreased by sildenafil. The peak oxygen consumption at maximal exercise and exercise time were significantly increased and the ventilation to carbon dioxide production slope was significantly decreased during peak exercise treadmill. The study concluded that the decrease in the heart rate during exercise observed with sildenafil could reduce the myocardial oxygen demand and lead to less ischemia.

Hirata et $a l .{ }^{36}$ studied the effects of sildenafil on cardiac function in HF patients. Twenty patients with ejection fraction $<35 \%$ were studied in a double-blind, placebo-controlled, crossover study. Cardiac output was measured with echocardiography after either $50 \mathrm{mg}$ of sildenafil or placebo. Sildenafil increased cardiac index by approximately $16 \%$ and decreased total systemic vascular resistance (SVR). The study concluded that patients with $\mathrm{HF}$ on sildenafil might have an increase in exercise tolerance because of a decrease in SVR and reduced afterload leading to an increase in cardiac index.

Katz et al. ${ }^{3}$ performed a study evaluating the effect of various doses of sildenafil on flow-mediated vasodilation in HF patients. This randomized, double-blind study analyzed the brachial artery flow-mediated vasodilation after 1,3 and 5 min of occlusion (cuff inflation) at baseline and $1 \mathrm{~h}$ after an oral dose of either 12.5, 25 or $50 \mathrm{mg}$ of sildenafil or placebo. There was a statistically significant increase in percentage of vasodilation in the $25 \mathrm{mg}$ $(3.3 \pm 1.9,3.8 \pm 1.8$ and $4.0 \pm 1.8 \%$ at 1,3 and $5 \mathrm{~min}$, respectively) and $50 \mathrm{mg}(3.7 \pm 1.3,4.1 \pm 1.1$ and $3.9 \pm 1.3 \%$, respectively) sildenafil groups compared to placebo $(0.7 \pm 1.1,0.2 \pm 1.2$ and $0.6 \pm 0.8 \%$, respectively) at all time intervals. This improvement of flow-mediated vasodilation is consistent with the decrease in SVR described by Hirata et al. ${ }^{36}$ and shows that sildenafil's ability to improve endothelial dysfunction extends to patients with HF.

Lewis et al. ${ }^{37}$ performed a study on the acute effects of sildenafil on HF patients. Thirteen patients with NYHA class III HF underwent invasive right heart hemodynamic monitoring, cardiopulmonary exercise testing and radionuclide ventriculography before and $1 \mathrm{~h}$ after $50 \mathrm{mg}$ of sildenafil. Sildenafil significantly decreased resting mean pulmonary artery pressure, pulmonary vascular resistance (PVR), SVR and increased cardiac index. Also, sildenafil significantly decreased exercise mean pulmonary artery pressure, PVR, PVR/SVR ratio and increased exercise cardiac index. The hemodynamics improved without significant changes in resting or exercise mean arterial pressure, resting heart rate or pulmonary capillary wedge pressure. Sildenafil also increased peak oxygen consumption at maximal exercise and decreased the ventilation to carbon dioxide production slope. When the patients were stratified to either having pulmonary hyper- tension (defined as a resting pulmonary artery pressure $>25 \mathrm{~mm} \mathrm{Hg}$ ) or not, the hemodynamic effects were predominantly observed in the patients with pulmonary hypertension. There was a statistically significant rise in rest and exercise right ventricular ejection fraction after treatment with sildenafil in patients with pulmonary hypertension. The authors concluded that sildenafil's effects on patients with HF are mainly due to an improved pulmonary artery pressure, and may be of benefit to HF patients with secondary pulmonary hypertension.

Al-Hesayen et $a .^{38}$ evaluated the effects of intravenous sildenafil on hemodynamics and sympathetic activity in HF patients. Ten patients received intravenous sildenafil and had right heart catheterizations and norepinephrine spillover rates calculated. There was a significant reduction in right atrial pressure, mean pulmonary artery pressure, mean arterial pressure and PVR/SVR ratio, with a significant increase in cardiac index. Also, there was a significant reduction in cardiac norepinephrine spillover. The study concluded that sildenafil acutely reduced pulmonary artery pressure without increasing cardiac sympathetic activity.

These studies show PDE-5 inhibition in HF leads to improved endothelial function, as well as decreased pulmonary artery pressure and improved cardiac index.

\section{Long-term studies}

The following studies revealed PDE-5 inhibitor's effect in longer-term studies (Table 3). Behling et $a .^{39}$ performed a study that analyzed the effects of sildenafil treatment for 4 weeks in HF patients. This double-blind, placebo-controlled study included 19 patients with HF who were randomized to placebo or $50 \mathrm{mg}$ of sildenafil three times daily. Patients underwent cardiopulmonary exercise testing and echocardiography at baseline and after 4 weeks of therapy. Sildenafil caused a significant improvement in oxygen consumption and a decrease in the ventilation to carbon dioxide production slope and echocardiography-derived systolic pulmonary artery pressure after 4 weeks of treatment. The study concluded that with 4 weeks of PDE-5 inhibitor therapy, patients with HF had improved exercise capacity and reduced pulmonary hypertension.

Guazzi et al. ${ }^{40}$ evaluated the effects of sildenafil over 6 months in patients with HF. A total of 46 patients were randomized to placebo or $50 \mathrm{mg}$ of sildenafil three times daily and had recorded measurements of flow-mediated vasodilation and cardiopulmonary exercise testing at baseline, 3 and 6 months. Sildenafil increased peak oxygen consumption and flow-mediated vasodilation with significant decreases in systolic pulmonary artery 
pressure and ventilation to carbon dioxide production slope. No serious adverse events were recorded. Three patients complained of flushing during the 6 -month period. The authors concluded that chronic sildenafil was safe to administer to HF patients and would also improve pulmonary hypertension and exercise tolerance leading to an improved quality of life.

Lewis et al. ${ }^{41}$ examined the effects of sildenafil in HF patients with secondary pulmonary hypertension. In this double-blind study, 34 patients with pulmonary artery pressure $>25 \mathrm{~mm} \mathrm{Hg}$ were randomized to either placebo or sildenafil, with a starting dose of $25 \mathrm{mg}$ and titrated up to a maximum dose of $75 \mathrm{mg}$ three times daily. Before starting either sildenafil or placebo, patients performed cardiopulmonary exercise testing with concurrent hemodynamic monitoring, radionuclide ventriculography and Minnesota Living with Heart Failure Questionnaire. These tests were repeated after 12 weeks of therapy. Sildenafil significantly increased the peak oxygen consumption, 6 min walking distance, peak exercise cardiac output, and stroke volume; and significantly decreased resting and exercise PVR and PVR to SVR ratio. These parameters occurred without a significant change in heart rate, arterial pressure, pulmonary artery pressure, pulmonary capillary wedge pressure, or cardiac index. The patients who received sildenafil also showed a significant improvement in right ventricular ejection fraction and Minnesota Living with Heart Failure Questionnaire as compared to placebo. The authors concluded that PDE-5 inhibitors provide an innovative approach to treating HF patients with secondary pulmonary hypertension.

The above studies demonstrated the beneficial cardiopulmonary effects of sildenafil in patients with HF (Table 3). Whether these benefits persist for more than 1 year remains to be determined. In addition, there is a lack of data in the literature regarding the effect of vardenafil or tadalafil in $\mathrm{HF}$ patients. Future studies should include all three PDE-5 inhibitors as well as determine the effect of the PDE-5 inhibitors on major adverse cardiac events and mortality. This may be accomplished with a long-term survival study of patients with HF randomized to standard HF therapy and placebo versus standard HF therapy plus a PDE-5 inhibitor.

\section{Mechanisms of PDE-5 inhibitors improving $\mathrm{HF}$}

The exact mechanism(s) by which PDE-5 inhibitors improve HF are unknown. Several possibilities have been described in the literature. Studies show that PDE-5 inhibitors improve endothelial dysfunction in HF patients. Better endothelial function leads to improved vasodilatory response of the vasculature to endogenous nitric oxide, which overcomes nitric oxide resistance and tolerance seen in HF patients. ${ }^{42}$ Better arterial vasodilation leads to improved afterload reduction, which allows improved forward stroke volume leading to an increased cardiac output. Better preload reduction by venous dilation leads to reduced venous and pulmonary congestion with decreased right ventricular pressures. Preload and afterload reduction individually lead to a decrease in myocardial wall stress, which lowers myocardial oxygen demand. ${ }^{43,44}$

There has been debate in the literature regarding whether PDE-5 is present in the myocardial cell. Wallis et $a l^{45}$ revealed that PDE-5 was not found in the cytosol of human myocardial cells and that sildenafil had no effect on the contractility of the trabeculae carneae of dogs. However, Nagendran et $a .^{46}$ showed that PDE-5 is upregulated in the myocardial cells of human hypertrophied right ventricles from patients with primary pulmonary hypertension, congenital heart disease or rheumatic valve disease. The authors also showed that PDE-5 inhibition with sildenafil led to a statistically significant increase in contractility in a modified right ventricular Langendorff preparation. The rise in right ventricular contractility was due to an intrinsic myocardial effect because the pulmonary arteries were no longer present and could therefore not contribute to reduced right ventricular afterload. Pokreisz et al. ${ }^{47}$ confirmed that PDE-5 expression is greater in left ventricular myocardium of patients with HF compared to controls. To determine the impact of elevated PDE-5 levels in diseased left ventricles, the authors compared the effect of a myocardial infarction on mice with increased PDE-5 expression versus wild type. The study showed that left ventricular end-systolic and end-diastolic volumes were significantly larger in the mice with PDE-5 overexpression compared to the wild-type mice 10 weeks after myocardial infarction, which suggested adverse left ventricular remodeling due to PDE-5.

Cardiac hypertrophy occurs when the myocardium is challenged with elevated wall stress. Borlaug et al. $^{48}$ demonstrated in 35 randomized, double-blinded, placebo-controlled healthy male volunteers that sildenafil dampened the acute myocardial response to dobutamine. Inhibiting adrenergic stimulation of the myocardium inhibits myocardial hypertrophy; inhibiting hypertrophy may improve HF. In a study by Takimoto et al., ${ }^{49}$ mice underwent transaortic constriction to induce pressure overload in the heart. Some mice were treated with either placebo or sildenafil immediately after surgery for 9 weeks. Another group of mice were treated 1 week after surgery with either placebo or sildenafil for 2 weeks. Mice that began receiving sildenafil immediately after surgery had significantly less hypertrophy and chamber remodeling compared to controls suggesting that silde- 
nafil prevents hypertrophy in high-pressure hearts. The mice that received sildenafil 1 week after surgery showed a gradual decline in the left ventricular wall mass, thickness and fractional shortening revealing that sildenafil can reverse established hypertrophy. Proposed mechanism for the effect on hypertrophy is that increases in intramyocardial guanosine $3^{\prime}, 5^{\prime}$-cyclic monophosphate lead to inhibition of hypertrophy-causing signaling pathways.

In summary, the mechanism by which PDE-5 inhibitors improve HF may be multifactorial. Studies revealed that sildenafil has similar effects on preload and afterload as classic HF medications. Also PDE-5 inhibitors appear to have an intrinsic effect on diseased myocardium by increasing contractility as well as inhibiting and even reversing cardiac hypertrophy.

\section{Role of PDE-5 inhibitors in pulmonary hypertension}

The role of PDE-5 inhibitors for the treatment of pulmonary hypertension has been established. Galiè et $a l^{50}$ completed a double-blind, placebo-controlled, multicenter, randomized study comparing the effect of various doses of sildenafil versus placebo on the 6 min walk, mean pulmonary artery pressure and World Health Organization functional class in patients with pulmonary hypertension. The causes of the pulmonary hypertension in this study population were either repaired congenital shunt, connectivetissue disease or idiopathic. Pulmonary hypertension was defined as a mean pulmonary artery pressure $>25 \mathrm{~mm} \mathrm{Hg}$ and a pulmonary capillary wedge pressure of $<15 \mathrm{~mm} \mathrm{Hg}$. After 12 weeks of treatment there were significant increases in the distance walked in $6 \mathrm{~min}$, significant decreases in mean pulmonary artery pressure and significant improvement in the World Health Organization functional class at all three dose levels of sildenafil when compared to placebo. Patients who completed the 12 weeks were offered the opportunity to enroll in an extension study. The 6 min walk test was repeated after 1 year of treatment and the exercise capacity was sustained. The study concluded that sildenafil is effective and safe for treating pulmonary hypertension. Sildenafil was approved by the Food and Drug Administration for the treatment of pulmonary hypertension in the form of Revatio (sildenafil citrate; Pfizer, New York, NY, USA) $20 \mathrm{mg}$ three times daily.

Table 4 summarizes the studies evaluating the effects of the other PDE-5 inhibitors on pulmonary hypertension. Ghofrani et al. ${ }^{51}$ demonstrated the importance of studying each drug's specific effect on cardiovascular diseases, given their differences on various hemodynamic parameters. Aizawa et al. ${ }^{52}$ confirmed Ghofrani et al.'s ${ }^{51}$ finding that vardenafil is not specific to the pulmonary vasculature in the acute setting, but with chronic treatment, only the pulmonary artery pressure and PVR were decreased. The case studies have demonstrated the potential role of tadalafil in patients with severe pulmonary hypertension. ${ }^{53,54}$

\section{Summary}

The PDE-5 inhibitors have revolutionized the treatment of ED; however their role in the treatment of cardiovascular diseases has yet to be determined. It is important that clinicians understand that ED is very common in the HF population, and therefore physicians should ask their patients about ED. PDE5 inhibitors are safe and effective therapy for ED in patients with mild to moderate $\mathrm{HF}$ and who are at low cardiac risk. PDE-5 inhibitors should be used with caution in cases of intermediate risk, and should be avoided in patients with high risk or are concurrently being treated with nitrates. Sildenafil is effective in improving the quality of life, exercise

Table 4 Additional PDE-5 inhibitor and pulmonary hypertension studies

\begin{tabular}{ll}
\hline Study & Findings \\
\hline Ghofrani et al. ${ }^{51}$ & $\begin{array}{l}\text { Each PDE-5 inhibitor has different acute effects on patients with pulmonary hypertension. All three reduced PVR, } \\
\text { yet only sildenafil and tadalafil reduced PVR/SVR ratio. }\end{array}$ \\
Aizawa et al. ${ }^{52}$ & $\begin{array}{l}\text { Vardenafil decreased both PVR and SVR acutely; chronic treatment reduced PVR/SVR ratio in patients with } \\
\text { pulmonary hypertension, suggesting a greater effect on PVR. }\end{array}$ \\
Affuso et al. $^{53}$ & $\begin{array}{l}\text { Case report of an idiopathic pulmonary hypertension patient treated with } 20 \text { mg of tadalafil every other day for } 6 \\
\text { months who had a drop in pulmonary artery pressure from } 100 \text { to } 76 \text { mm Hg. }\end{array}$ \\
& $\begin{array}{l}\text { Two case reports: a patient with idiopathic pulmonary hypertension treated with } 30 \text { mg of tadalafil daily for } 3 \\
\text { months had a decrease in pulmonary artery pressure from } 131 \text { to } 92 \text { mm Hg. A patient with Eisenmenger's disease } \\
\text { treated with } 20 \text { mg of tadalafil daily for } 3 \text { months had a decrease in pulmonary artery pressure from 130 to }\end{array}$ \\
& 85 mm Hg.
\end{tabular}

Abbreviations: PDE-5, phosphodiesterase type 5; PVR, pulmonary vascular resistance; SVR, systemic vascular resistance. 
tolerance and hemodynamics of HF patients, especially patients with pulmonary hypertension. However whether the other PDE-5 inhibitors have this same benefit remains to be determined. Studies have shown that it is safe to treat HF patients with sildenafil in a chronic setting; however whether PDE-5 inhibitors decrease mortality or major adverse cardiac events has not been established. The exact mechanism by which PDE-5 inhibitors improve HF is unknown but may be related to improved endothelial function, reduced preload, reduced afterload or some direct effect on the diseased myocardium. Studies have shown that sildenafil is effective in treating pulmonary hypertension, but sildenafil's effect on mortality in these patients also is unknown. Each of the PDE-5 inhibitors may affect the hemodynamics of pulmonary hypertension in a different manner.

\section{Recommendations}

For patients with mild to intermediate HF who do not require nitrate therapy and have ED, it is safe and effective to treat the ED with PDE-5 inhibitors (excluding patients with hypertrophic obstructive cardiomyopathy or aortic stenosis). Patients with severe HF should avoid treatment with PDE-5 inhibitors until the HF is improved. Currently the only PDE-5 inhibitor that is approved for pulmonary hypertension is sildenafil. Further studies are necessary to determine if tadalafil or vardenafil improve exercise capacity, functional class and hemodynamics as well as sildenafil in patients with pulmonary hypertension. Although the data currently suggest that PDE-5 inhibitors can improve hemodynamics, exercise capacity and functional class in HF patients, additional studies are needed to determine if PDE-5 inhibitors should be a standard part of HF therapy.

\section{Conflict of interest}

Dr Kloner has been a speaker/consultant for Pfizer (New York, NY, USA) and Lilly (Indianapolis, IN, USA) and has received grant support from Lilly.

\section{References}

1 Lue TF. Erectile dysfunction. N Engl J Med 2000; 342: 18021813.

2 Goldstein I, Lue TF, Padma-Nathan H, Rosen RC, Steers WD, Wicker PA. Oral sildenafil in the treatment of erectile dysfunction. Sildenafil Study Group. N Engl J Med 1998; 338: 1397-1404.

3 Katz SD, Balidemaj K, Homma S, Wu H, Wang J, Maybaum S. Acute type 5 phosphodiesterase inhibition with sildenafil enhances flow-mediated vasodilation in patients with chronic heart failure. J Am Coll Cardiol 2000; 36: 845-851.
4 Rosano GM, Aversa A, Vitale C, Fabbri A, Fini M, Spera G. Chronic treatment with tadalafil improves endothelial function in men with increased cardiovascular risk. Eur Urol 2005; 47: 214-220.

5 Aversa A, Greco E, Bruzziches R, Pili M, Rosano G, Spera G. Relationship between chronic tadalafil administration and improvement of endothelial function in men with erectile dysfunction: a pilot study. Int J Impot Res 2007; 19: 200-207.

6 Mazo E, Gamidov S, Iremashvili V. The effect of vardenafil on endothelial function of brachial and cavernous arteries. Int $J$ Impot Res 2006; 18: 464-469.

7 Billups KL. Erectile dysfunction as an early sign of cardiovascular disease. Int J Impot Res 2005; 17: S19-S24.

8 Kloner RA. Erectile dysfunction as a predictor of cardiovascular disease. Int J Impot Res 2008; 20: 460-465.

9 Kloner R, Padma-Nathan H. Erectile dysfunction in patients with coronary artery disease. Int J Impot Res 2005; 17: 209-215.

10 Kloner R. Erectile dysfunction and hypertension. Int J Impot Res 2007; 19: 296-302.

11 Rastogi S, Rodriguez JJ, Kapur V, Schwarz ER. Why do patients with heart failure suffer from erectile dysfunction? A critical review and suggestions on how to approach this problem. Int $J$ Impot Res 2005; 17: S25-S36.

12 Rosamond W, Flegal K, Furie K, Go A, Greenlund K, Haase N et al. Heart disease and stroke statistics-2008 update: a report from the American Heart Association Statistics Committee and Stroke Statistics Subcommittee. Circulation 2008; 117: e25-146.

13 Feldman HA, Goldstein I, Hatzichristou DG, Krane RJ, McKinlay JB. Impotence and its medical and psychosocial correlates: results of the Massachusetts Male Aging Study. J Urol 1994; 151: 54-61.

14 Jaarsma T, Dracup K, Walden J, Stevenson LW. Sexual function in patients with advanced heart failure. Heart Lung 1996; 25 : 262-270.

15 Herbert K, Lopez B, Castellano J, Palacio A, Tamari L, Arcemen LM. The prevalence of erectile dysfunction in heart failure patients by race and ethnicity. Int J Impot Res 2008; 20: 507-511.

16 Schwarz ER, Kapur V, Bionat S, Rastogi S, Gupta R, Rosanio S. The prevalence and clinical relevance of sexual dysfunction in women and men with chronic heart failure. Int J Impot Res 2008; 20: 85-91.

17 Goldstein I. The mutually reinforcing triad of depressive symptoms, cardiovascular disease, and erectile dysfunction. Am J Cardiol 2000; 86: 41F-45F.

18 Schwarz ER, Rastogi S, Kapur V, Sulemanjee N, Rodriguez JJ. Erectile dysfunction in heart failure patients. J Am Coll Cardiol 2006; 48: 1111-1119.

19 Grimm Jr RH, Grandits GA, Prineas RJ, McDonald RH, Lewis $\mathrm{CE}$, Flack JM et al. Long-term effects on sexual function of five antihypertensive drugs and nutritional hygienic treatment in hypertensive men and women. Treatment of Mild Hypertension Study (TOMHS). Hypertension 1997; 29: 8-14.

20 Gupta S, Salimpour P, Saenz de Tejada I, Daley J, Gholami S, Baller $\mathrm{M}$ et al. A possible mechanism for alteration of human erectile function by digoxin: inhibition of corpus cavernosum sodium/potassium adenosine triphosphate activity. J Urol 1998; 159: 1529-1536.

21 Muguruma H, Kawanishi Y, Sugiyama H, Kagawa J, Tanimoto $\mathrm{S}$, Yamanaka $\mathrm{M}$ et al. Effect of aldosterone on isolated human penile corpus cavernosum tissue. BJU Int 2008; 102: 500-503.

22 Brixius K, Middeke M, Lichtenthal A, Jahn E, Schwinger RHG. Nitric oxide, erectile dysfunction and beta-blocker treatment (MR NOED study): benefit of nebivolol versus metoprolol in hypertensive men. Clin Exp Pharmacol Physiol 2007; 34: 327-331.

23 Baumhäkel M, Schlimmer N, Böhm M. Effect of irbesartan on erectile function in patients with hypertension and metabolic syndrome. Int J Impot Res 2008; 20: 493-500. 
24 Toblli JE, Stella I, Mazza ON, Ferder L, Inserra F. Different effect of losartan and amlodipine on penile structures in male spontaneously hypertensive rats. Am J Nephrol 2004; 24: 614-623.

25 Toblli JE, Cao G, Casas G, Mazza ON. In vivo and in vitro effects of nebivolol on penile structures in hypertensive rats. Am J Hypertens 2006; 19: 1226-1232.

26 Kostis JB, Jackson G, Rosen R, Barrett-Connor E, Billups K, Burnett AL et al. Sexual dysfunction and cardiac risk (the Second Princeton Consensus Conference). Am J Cardiol 2005; 96: $313-321$.

27 Mandras SA, Uber PA, Mehra MR. Sexual activity and chronic heart failure. Mayo Clin Proc 2007; 82: 1203-1210.

28 Cremers B, Kjellstrom B, Sudkamp M, Bohm M. Hemodynamic monitoring during sexual intercourse and physical exercise in a patient with chronic heart failure and pulmonary hypertension (letter). Am J Med 2002; 112: 428-430.

29 Katz SD, Parker JD, Glasser DB, Bank AJ, Sherman N, Wang H et al. Efficacy and safety of sildenafil citrate in men with erectile dysfunction and chronic heart failure. Am J Cardiol 2005; 95: 36-42.

30 Webster LJ, Michelakis ED, Davis T, Archer SL. Use of sildenafil for safe improvement of erectile function and quality of life in men with New York Heart Association classes II and III congestive heart failure: a prospective, placebo-controlled, double-blind crossover trial. Arch Intern Med 2004; 164: 514-520.

31 Freitas D, Athanazio R, Almeida D, Dantas N, Reis F. Sildenafil improves quality of life in men with heart failure and erectile dysfunction. Int J Impot Res 2006; 18: 210-212.

32 Cheitlin MD, Hutter Jr. AM, Brindis RG, Ganz P, Kaul S, Russell RO et al. ACC/AHA expert consensus document. Use of sildenafil (Viagra) in patients with cardiovascular disease. American College of Cardiology/American Heart Association. J Am Coll Cardiol 1999; 33: 273-282.

33 Kloner RA. Cardiovascular effects of the 3 phosphodiesterase5 inhibitors approved for the treatment of erectile dysfunction. Circulation 2004; 110: 3149-3155.

34 Kloner RA, Hutter AM, Emmick JT, Mitchell MI, Denne J, Jackson G. Time course of the interaction between tadalafil and nitrates. J Am Coll Cardiol 2003; 42: 1855-1860.

35 Bocchi EA, Guimaraes G, Mocelin A, Bacal F, Bellotti G, Ramires JF. Sildenafil effects on exercise, neurohormonal activation, and erectile dysfunction in congestive heart failure: a double-blind, placebo-controlled, randomized study followed by a prospective treatment for erectile dysfunction. Circulation 2002; 106: 1097-1103.

36 Hirata K, Adji A, Vlachopoulos C, O’Rourke MF. Effect of sildenafil on cardiac performance in patients with heart failure. Am J Cardiol 2005; 96: 1436-1440.

37 Lewis GD, Lachmann J, Camuso J, Lepore JJ, Shin J, Martinovic ME et al. Sildenafil improves exercise hemodynamics and oxygen uptake in patients with systolic heart failure. Circulation 2007; 115: 59-66.

38 Al-Hesayen A, Floras JS, Parker JD. The effects of intravenous sildenafil on hemodynamics and cardiac sympathetic activity in chronic human heart failure. Eur $J$ Heart Fail 2006; 8: 864-868.

39 Behling A, Rohde LE, Colombo FC, Goldraich LA, Stein R, Clausell N. Effects of $5^{\prime}$-phosphodiesterase four-week long inhibition with sildenafil in patients with chronic heart failure: a double-blind, placebo-controlled clinical trial. J Card Fail 2008; 14: 189-197.

40 Guazzi M, Samaja M, Arena R, Vicenzi M, Guazzi MD. Longterm use of sildenafil in the therapeutic management of heart failure. J Am Coll Cardiol 2007; 50: 2136-2144.

41 Lewis GD, Shah R, Shahzad K, Camuso JM, Pappagianopoulos PP, Hung J et al. Sildenafil improves exercise capacity and quality of life in patients with systolic heart failure and secondary pulmonary hypertension. Circulation 2007; 116: $1555-1562$.

42 Katz SD. Potential role of type 5 phosphodiesterase inhibition in the treatment of congestive heart failure. CHF 2003; 9: 9-15.

43 Iyengar S, Haas GJ, Young JB. Acute heart failure. In: Topol EJ (ed). Textbook of Cardiovascular Medicine 3rd edn. Lippincott Williams \& Wilkins: Philadelphia, 2007, pp 1352-1372.

44 Mason DT. Afterload reduction and cardiac performance. Physiologic basis of systemic vasodilators as a new approach in treatment of congestive heart failure. Am J Med 1978; 65: 106-125.

45 Wallis RM, Corbin JD, Francis SH, Ellis P. Tissue distribution of phosphodiesterase families and the effects of sildenafil on tissue cyclic nucleotides, platelet function, and the contractile responses of trabeculae carneae and aortic rings in vitro. Am J Cardiol 1999; 83: 3C-12C.

46 Nagendran J, Archer SL, Soliman D, Gurtu V, Moudgil R, Haromy A et al. Phosphodiesterase type 5 is highly expressed in the hypertrophied human right ventricle, and acute inhibition of phosphodiesterase type 5 improves contractility. Circulation 2007; 116: 238-248.

47 Pokreisz P, Vandenwijngaert S, Bito V, Van den Bergh A, Lenaerts I, Busch C et al. Ventricular phosphodiesterase-5 expression is increased in patients with advanced heart failure and contributes to adverse ventricular remodeling after myocardial infarction in mice. Circulation 2009; 119: 408-416.

48 Borlaug BA, Melenovsky V, Marhin T, Fitzgerald P, Kass DA. Sildenafil inhibits $\beta$-adrenergic-stimulated cardiac contractility in humans. Circulation 2005; 112: 2642-2649.

49 Takimoto E, Champion HC, Li M, Belardi D, Ren S, Rodriguez ER et al. Chronic inhibition of cyclic GMP phosphodiesterase 5A prevents and reverses cardiac hypertrophy. Nat Med 2005; 11: $214-222$

50 Galiè N, Ghofrani HA, Torbicki A, Barst RJ, Rubin LJ, Badesch D et al. Sildenafil citrate therapy for pulmonary arterial hypertension. N Engl J Med 2005; 353: 2148-2157.

51 Ghofrani HA, Voswinckel R, Reichenberger F, Olschewski H, Haredza P, Karadas B et al. Differences in hemodynamic and oxygenation responses to three different phosphodiesterase-5 inhibitors in patients with pulmonary arterial hypertension: a randomized prospective study. J Am Coll Cardiol 2004; 44: 1488-1496.

52 Aizawa K, Hanaoka T, Kasai H, Kogashi K, Kumazaki S, Koyama J et al. Long-term vardenafil therapy improves hemodynamics in patients with pulmonary hypertension. Hypertens Res 2006; 29: 123-128.

53 Affuso F, Palmieri EA, Di CP, Guardasole V, Fazio S. Tadalafil improves quality of life and exercise tolerance in idiopathic pulmonary arterial hypertension. Int $J$ Cardiol 2006; 108: 429-431.

54 Singh TS, Kumar D, Basu S, Panja M, Mitra B. Tadalafil in the management of severe pulmonary artery hypertension. Indian Heart J 2006; 58: 52-53. 